\title{
Inhibition of Copper Pitting Corrosion in Aggressive Potable Waters
}

\author{
Emily Sarver $^{1}$ and Marc Edwards ${ }^{2}$ \\ ${ }^{1}$ Department of Mining and Minerals Engineering, Virginia Tech University, 108 Holden Hall, Blacksburg, VA 24061, USA \\ ${ }^{2}$ Department of Civil and Environmental Engineering, Virginia Tech University, 418 Durham Hall, Blacksburg, VA 24061, USA
}

Correspondence should be addressed to Emily Sarver, esarver@vt.edu

Received 2 December 2011; Accepted 23 April 2012

Academic Editor: Flavio Deflorian

Copyright (C) 2012 E. Sarver and M. Edwards. This is an open access article distributed under the Creative Commons Attribution License, which permits unrestricted use, distribution, and reproduction in any medium, provided the original work is properly cited.

\begin{abstract}
Copper pitting corrosion can lead to premature plumbing failures, and can be caused by aggressive potable waters characterized by high $\mathrm{pH}$, free chlorine residual and low alkalinity. In such waters and under continuous flow, certain inhibitors including phosphate, silica or natural organic matter may greatly reduce pitting occurrence. In the current work, $1 \mathrm{mg} / \mathrm{L}$ phosphate (as $\mathrm{P}$ ) completely prevented initiation of pits, and $5 \mathrm{mg} / \mathrm{L}$ silica (as Si) significantly decelerated pitting. However, much lower doses of these inhibitors had little benefit and actually accelerated the rate of attack in some cases. Effects of organic matter were dependent on both the type (e.g., natural versus ozonated humic substances) and dosage. Dose-response effects of free chlorine and alkalinity were also investigated. Based on electrochemical data, pits initiated more rapidly with increased free chlorine, but even moderate levels of chlorine $(\sim 0.4 \mathrm{mg} / \mathrm{L})$ eventually caused severe pitting. High alkalinity decreased pit propagation rates but did not prevent pit formation.
\end{abstract}

\section{Introduction}

Copper pitting corrosion in potable water plumbing systems is problematic because it can lead to fully-penetrating pinhole leaks, which burden consumers with the expense and frustration of repairing or replacing plumbing materials, water damage, and associated mold growth [1]. While there is ample reason to believe that there are at least a few "causes" of pitting, only that of aggressive water characterized by high $\mathrm{pH}$, free chlorine, and low alkalinity has been reproduced in the laboratory using synthesized waters [2-5]. Potential mitigation strategies that can counter the corrosivity of such waters have not been examined in detail.

Generally speaking, mitigation strategies involving water chemistry modifications are very attractive because the risk of pinhole leaks could be reduced for homes throughout an entire distribution system. This is much more appealing than expecting consumers to treat their water to reduce corrosivity, or to gradually replace or repair their plumbing system assets. Depending on the extent of pitting in a system, water chemistry modifications can also represent relatively low-cost solutions. In addition to the obvious possibilities of reducing free chlorine residual or $\mathrm{pH}$ [2], recent research by Lytle and Schock has suggested that increasing alkalinity can reduce pitting rates in high $\mathrm{pH}$ waters with chlorine [3]. Several other constituents including phosphate [3, 57], silica (silicate at high $\mathrm{pH}$ ) $[5,8]$, and natural organic matter (NOM) [9-11] may also act as inhibitors to pitting at ambient concentrations or those achieved by inhibitor dosing. Table 1 shows typical ranges of these constituents in source waters and treated potable waters as well as concentrations below or above which copper pitting has been observed to occur.

Forensic evidence is necessary in practical investigations of copper pitting corrosion in plumbing applications [5]. While pipe-loop studies offer a proven means gathering meaningful forensic data [3], they have seldom provided mechanistic insights to pitting reactions. However, insights from older theory $[12,13]$, as refined and confirmed in recent electrochemical studies $[4,14]$, may be utilized as a conceptual framework for interpreting and analyzing pipeloop data relative to pit initiation and propagation phases. 


\section{Theory}

2.1. Copper Pit Initiation and Propagation. Copper pitting is generally regarded as a two-step process in which pits are first formed (i.e., initiation) and then gradually penetrated through a metal surface (i.e., propagation). While initiation mechanisms are not well understood, and likely vary depending on physical and chemical exposure conditions, propagation proceeds via coupling of anodic reactions (i.e., copper oxidation) occurring at small anode sites (i.e., the pits) with cathodic reactions (i.e., oxygen or free chlorine reduction) occurring on relatively large surface areas [15]. This differs from uniform copper corrosion, for which anodic and cathodic reactions effectively occur equally over the pipe surface. Pits can initiate at specific locations, including imperfections or breakdowns in the passive film layer that naturally occurs on copper surfaces in potable water or under particulate deposits that have settled onto the pipe surface.

After initiation, pit propagation can be enhanced by differential concentration cells, due to dramatic chemical changes that occur in the very small volume of water localized inside the growing pit. Specifically, the pit water becomes very acidic due to Lewis acidity of released $\mathrm{Cu}^{+1}$ and $\mathrm{Cu}^{+2}$ ions, and ionic strength increases due to anion (e.g., $\mathrm{Cl}^{-}$and $\mathrm{SO}_{4}{ }^{2-}$ ) transport to the pit to maintain electroneutrality $[13,15,16]$. In certain cases, the acidic and salty environment can promote sustained corrosion in the pit, and precipitation of copper salts (e.g., $\mathrm{CuOH}$ ) forms a distinct mound of corrosion by-products (i.e., a tubercle).

It is fairly well established that a characteristic rise in corrosion potential (i.e., $E_{\text {corr }}$ ) that proceeds beyond a critical threshold value (i.e., $\left.E_{\text {pit }}\right)$ is necessary to initiate pitting in some circumstances $[13,17,18]$. Although this phenomenon might not be associated with all types of pitting in potable water systems [19], several studies have convincingly linked $E_{\text {corr }}$ rise to pitting caused by the aggressive combination of high $\mathrm{pH}$, low alkalinity, and free chlorine [2-5]. Moreover, Cong et al. has recently conducted elegant studies using cyclic voltammetry (CV) and coupled multielectrode arrays (CMEA), which elucidated $E_{\text {pit }}$ (or effective $E_{\text {pit }}$ ) values for copper in this water type $[4,14]$. Thus, trends in $E_{\text {corr }}$ can be evaluated to help delineate the distinct phases of pitting during pipe-loop testing.

2.2. Anodic and Cathodic Inhibitors. Inhibitors naturally present in water supplies, or which are added to mitigate corrosion, may prevent pitting by interfering with any aspect of the electrochemical cell, including (1) preventing the transport of anions that could accelerate corrosion into the pit or (2) blocking the oxidation and/or reduction reaction sites. A basic example of the former mechanism would be transport of bicarbonate into the pit instead of chloride or sulfate, potentially reducing the extent of the $\mathrm{pH}$ drop. With respect to the latter, in some simple conceptualizations, it is hypothesized that "anodic pitting inhibitors" are negatively charged species (e.g., $\mathrm{PO}_{4}{ }^{3-}, \mathrm{SiO}_{3}{ }^{2-}$ ) that would be drawn to the net positive charge at an anode site (i.e., where $\mathrm{Cu}^{+}$ and/or $\mathrm{Cu}^{2+}$ cations are being released) where they stifle the anodic reaction. Conversely, "cathodic pitting inhibitors" are positively charged species (e.g., $\mathrm{Zn}^{2+}$ ) that are drawn to the net negative charge at cathode sites (Figure 1) where they somehow stifle the cathodic reaction.

If pitting corrosion is limited by the rate of cathodic reactions, as is often assumed to be the case, any dose of cathodic inhibitor(s) is expected to reduce initiation and propagation of pitting. However, at low enough dosages of anodic inhibitors, inactivating some of the pit sites could increase the cathodic driving force for corrosion at a few surviving sites, thereby accelerating the rate of pit growth relative to a condition without any inhibitor at all [26]. For this reason, very low doses of anodic inhibitors might actually decrease the time-to-failure; so only at dosages high enough to inactivate all anodic sites are anodic inhibitors considered "safe." Beyond the idealized conceptualization of inhibitors presented above, it should be noted that some anions may function as cathodic inhibitors and some cations may function as anodic inhibitors if, for example, either is taken up into a protective film or passive scale layer that effectively passivates the entire metal surface. In this case, the effective constituents may be called "passivating" inhibitors [27].

Phosphate and silica are currently used by utilities to control various types of corrosion in potable water distribution systems (e.g., corrosion of iron mains) [28] (Table 1). The efficacy of these constituents in copper pitting mitigation has been suggested by several authors $[3,5,6]$ and some favorable data from full-scale testing [29]. Some research has also demonstrated that anionic NOM may also function as a very effective pitting inhibitor, even at relatively small concentrations $[9,11,12,30]$. However, to date, the dependency between dose and effectiveness for each of these constituents has not been established nor has substantive information been gathered as to their specific functions (i.e., as anodic or cathodic pitting inhibitors, or both). It is also of considerable interest to determine whether very low levels of these constituents might actually increase pitting propensity.

This research uses electrochemical measures and pipeloop testing to practically investigate aspects of pit initiation and growth. Specific goals were to (1) determine whether high levels of free chlorine residual were essential to initiating and/or propagating pitting in high $\mathrm{pH}$, low alkalinity water (2) examine the efficacy and dose-response effects of phosphate, silica, NOM, and increased alkalinity in inhibiting pitting in aggressive waters, and (3) draw preliminary conclusions regarding possible mechanisms of inhibition, and whether certain inhibitor dose ranges may actually increase pit growth rates.

\section{Materials and Methods}

Both large- and small-scale pipe-loop tests were conducted to examine the dose-response effects of free chlorine and potential natural and engineered inhibitors on copper pitting caused by the aggressive combination of high $\mathrm{pH}$, low alkalinity, and chlorine in potable water (Table 2). The large-scale loops exemplify more realistic conditions with 
TABLE 1: Typical ranges of constituents in source and treated waters, and ranges in which copper may be susceptible to pitting in chlorinated, high $\mathrm{pH}$, and low alkalinity water. Bolded values correspond to observations in the current work.

\begin{tabular}{|c|c|c|c|c|}
\hline Constituent & Presence in potable water & $\begin{array}{l}\text { Typical source water } \\
\text { range }(\mathrm{mg} / \mathrm{L})\end{array}$ & $\begin{array}{l}\text { Typical treated water } \\
\text { range }(\mathrm{mg} / \mathrm{L})\end{array}$ & $\begin{array}{l}\text { Pitting susceptibility } \\
(\mathrm{mg} / \mathrm{L})\end{array}$ \\
\hline Free chlorine (as $\mathrm{Cl}_{2}$ ) & Added as disinfectant & 0 & $1-4,[20]$ & $\begin{array}{c}\geq \mathbf{0 . 4} \\
\geq 1^{\mathrm{A}},[21] \\
\geq 2,[22]\end{array}$ \\
\hline Alkalinity (as $\left.\mathrm{CaCO}_{3}\right)$ & $\begin{array}{l}\text { Natural constituent; sometimes } \\
\text { added or removed via various } \\
\text { treatment processes }\end{array}$ & $0-400^{\mathrm{C}},[23]$ & $\begin{array}{l}\text { Generally similar to } \\
\text { source water }\end{array}$ & $\begin{array}{l}\leq 105^{\mathrm{B}},[3] \\
\quad \leq \mathbf{1 5 0}\end{array}$ \\
\hline Phosphate (as P) & $\begin{array}{l}\text { Natural constituent or } \\
\text { introduced by pollution; often } \\
\text { added as general corrosion } \\
\text { inhibitor for various distribution } \\
\text { materials }\end{array}$ & $0-0.5^{\mathrm{C}},[23]$ & $\leq 1,[24]$ & $\leq 0.1$ \\
\hline Silica (as Si) & $\begin{array}{l}\text { Natural constituent; sometimes } \\
\text { added as corrosion inhibitor; } \\
\text { sometimes removed due to } \\
\text { treatment interferences }\end{array}$ & $5-55^{\mathrm{C}},[23]$ & $\begin{array}{l}\text { Generally similar to } \\
\text { source water }\end{array}$ & $\leq 5$ \\
\hline Organic matter (as TOC) & $\begin{array}{l}\text { Natural constituent or } \\
\text { introduced by pollution; } \\
\text { removed due to taste/odor; } \\
\text { disinfectant by-product and/or } \\
\text { microbial issues }\end{array}$ & $0-10^{\mathrm{C}},[23]$ & $1-10^{\mathrm{D}},[25]$ & $\begin{array}{l}\text { Undetermined; } \\
\text { dependent on type of } \\
\text { organic present }\end{array}$ \\
\hline $\begin{array}{l}{ }^{A} \text { Determined in short-term, s } \\
{ }^{B} \text { Determined in long-term, co } \\
C^{C} \text { Identified as range between } \\
2011 \text { [23]; alkalinity and Si are } \\
\text { D Identified as range between }\end{array}$ & $\begin{array}{l}\text { CMEA tests at } \mathrm{pH} 9,34 \mathrm{mg} / \mathrm{L} \text { alkalinit } \\
\text { as flow pipe-loop tests at } \sim \mathrm{pH} 9, \sim 0.5 \\
\text { 95th percentiles from USGS Nationa } \\
\text { gulated and thus typically occur at sim }\end{array}$ & $\begin{array}{l}\left.\text { as } \mathrm{CaCO}_{3}\right)[21] \text {. } \\
\text { g/L Cl} 2,25 \mathrm{mg} / \mathrm{L} \mathrm{DIC} \\
\text { Water Quality data (gr } \\
\text { r concentrations in sou }\end{array}$ & $\begin{array}{l}\text { water, spring, stream) } \\
\text { and treated potable wat }\end{array}$ & lected between 1991 and \\
\hline
\end{tabular}

respect to a copper plumbing system (e.g., practical flow velocity, copper tube size and wall thickness, etc.), whereas the small-scale loops were designed to track formation of fully penetrating leaks under very aggressive conditions (e.g., higher flow velocity, thinner copper tube wall). A total of 10 large-scale tests with durations between 189 and 490 days, and 21 small-scale tests with durations between 86 and 220 days were conducted (Table 3 ). Since the goal was to determine time to pit breakthrough as a function of inhibitor dose, and each of these relatively large-scale tests were longterm (i.e., months to years) and are labor intensive, tests were not run in replicate (duplicate or triplicate), but critical conclusions developed at small-scale were subject to large scale confirmation experiments (see Table 3 ). For example, the control water was tested in both pipe-loop apparatuses, as were some critical conditions with added orthophosphate, silica, or organic matter. Prior work has demonstrated that both the small and large pipe loops provide reproducible results and that the small-scale loops are particularly useful for gaining insights regarding trends in relatively short-time periods (i.e., months instead of years) [5].

3.1. Water Qualities and Inhibitor Dosages. The control water quality (Table 2) was identical to the high $\mathrm{pH}$, high free chlorine water first shown by Marshall to cause pitting and pinhole leaks in copper [2], except that it did not contain aluminum solids. Only high and low concentrations of the test variables were investigated in the large-scale loops, but ranges of concentrations (except for in the case of alkalinity) were tested in the small loops. Additionally, three different types of organic matter were tested in the small loops: natural organic matter (NOM), ozonated NOM, and a combination of acetate and glucose.

Automatic feed systems and manual chemical adjustments were used to maintain targeted $\mathrm{pH}$ and free chlorine residuals. $\mathrm{pH}$ was measured using a double-junction Ag$\mathrm{AgCl}$ electrode and was generally maintained within 0.2 (standard deviation) units of the target (i.e., 9.2 \pm 0.2 ). Free chlorine residual was measured using a DPD (diethyl phenylene diamine) colorimetric test per standard method 4500-Cl G [31] with a Hach Chlorine Pocket Colorimeter II, and was maintained within $0.3 \mathrm{mg} / \mathrm{L}$ (standard deviation) of the targets (e.g., $4.0 \pm 0.3 \mathrm{mg} / \mathrm{L}$ ).

Bulk water was changed weekly in the small-scale loops, and either weekly, every two weeks, or every three weeks in the large-scale loops to limit the extent of chloride buildup due to free chlorine decay. Just before each water change, test waters were made up using deionized water and dry reagentgrade sodium or calcium salts. Free chlorine was added as sodium hypochlorite from a concentrated bleach stock (i.e., $6 \% \mathrm{NaOCl}$ solution). $\mathrm{pH}$ was adjusted using sodium hydroxide and nitric acid. Water samples were analyzed via inductively coupled plasma mass spectrometry (ICP-MS) for quality assurance.

Orthophosphate and silica were dosed as sodium phosphate and sodium silicate, respectively. A natural organic 
TABLE 2: Experimental conditions for large- and small-scale tests.

\begin{tabular}{|c|c|c|}
\hline \multirow{2}{*}{ Test variable } & \multicolumn{2}{|l|}{ Water quality } \\
\hline & Large-scale tests & Small-scale tests \\
\hline Control (values as $\mathrm{mg} / \mathrm{L}$ ) & $\mathrm{pH} 9.2$, free chlorine $\left(\right.$ as $\left.\mathrm{Cl}_{2}\right)=4, \mathrm{Ca}^{2+}=17, \mathrm{Na}^{2+}=16, \mathrm{Cl}^{-}=20, \mathrm{SO}_{4}{ }^{2-}$ & , alkalinity $=34\left(\right.$ as $\left.\mathrm{CaCO}_{3}\right)$ \\
\hline $\begin{array}{l}\text { Free chlorine adjusted } \\
\mathrm{mg} / \mathrm{L}\left(\text { as } \mathrm{Cl}_{2}\right)\end{array}$ & 0.4 & $0.5,1,2,3,8$ \\
\hline $\begin{array}{l}\text { Orthophosphate added } \\
\mathrm{mg} / \mathrm{L} \text { (as P) }\end{array}$ & $0.1,1$ & $0.015,0.025,0.1,0.25,0.5,1$ \\
\hline Silica added $\mathrm{mg} / \mathrm{L}$ (as $\mathrm{Si}$ ) & $0.5,5$ & $0.1,0.5,2.5,10$ \\
\hline $\begin{array}{l}\text { Organic matter added } \\
\mathrm{mg} / \mathrm{L} \text { (as TOC) }\end{array}$ & $0.01^{\mathrm{A}}, 0.1^{\mathrm{A}}$ & $0.005^{\mathrm{A}}, 0.1^{\mathrm{A}}, 0.05^{\mathrm{A}}, 0.05^{\mathrm{B}}, 0.05^{\mathrm{C}}$ \\
\hline $\begin{array}{l}\text { Alkalinity adjusted mg/L } \\
\left(\text { as } \mathrm{CaCO}_{3}\right)\end{array}$ & 10,150 & None \\
\hline
\end{tabular}

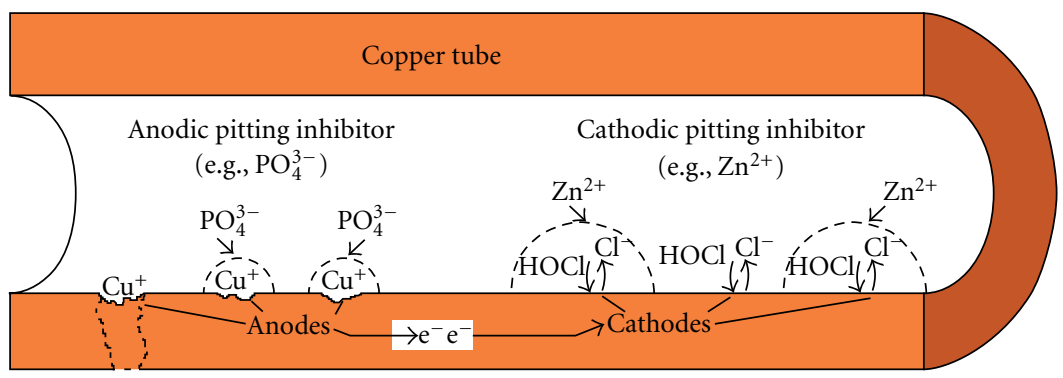

FIGURE 1: Simplified depiction of conventional wisdom regarding pit inhibition by anodic and cathodic inhibitors.

matter stock solution was made by chlorinating and filtering a concentrated humic stock (to $0.45 \mu \mathrm{m}$ ), such that the solution was relatively stable and homogeneous. In some water treatment operations, processes such as ozonation are used for primary disinfection and this process can break down the long chains of humic compounds in NOM, which in turn could alter its effectiveness as a natural pitting inhibitor. To investigate this, part of the above NOM stock was ozonated for several hours, until the resulting solution (referred to herein as ozonated NOM) had only 33\% of the $\mathrm{UV}_{254}$ absorbance of the unozonated NOM stock. To test the effects of model low molecular weight organic compounds on copper pitting, a solution of sodium acetate and d-glucose (58\% acetate, $42 \%$ glucose, by weight) was used.

3.2. Pipe Loops. Each large-scale pipe loop (Figure 2(a)) consisted of a $94 \mathrm{~L}$ polypropylene plastic reservoir, from which water was continuously recirculated through three $\left(1^{\prime}\right.$ or $\left.30.5 \mathrm{~cm}\right)$ lengths of $(3 / 4)^{\prime \prime}(1.9 \mathrm{~cm})$ diameter Type $\mathrm{M}$ copper tubing at a velocity of about $4.5 \mathrm{ft} / \mathrm{s}(1.3 \mathrm{~m} / \mathrm{s})$. Another short $\left(2^{\prime \prime}\right.$ or $\left.5.1 \mathrm{~cm}\right)$ length of the same copper tubing was located out-of-flow (i.e., at the dead-end $\mathrm{T}$ in Figure 2). All copper sections were physically separated using short lengths of clear vinyl tubing, but were electrically connected via external copper wires. Vinyl tubing also was used to connect copper to recirculation pumps (magnetdrive, centrifugal with polypropylene construction) and to complete flow loops. Reservoirs were closed to limit atmospheric influences on water quality (e.g., changes in alkalinity, temperature).

Small-scale pipe loops (Figure 2(b)) were similar in construction to the large loops but consisted of $30 \mathrm{~L}$ reservoirs and had only one short $\left(3^{\prime \prime}\right.$ or $\left.7.6 \mathrm{~cm}\right)$ length of $(1 / 4)^{\prime \prime}$ $(0.63 \mathrm{~cm})$ diameter copper tubing. Water was continuously recirculated by submersible pumps (magnet-drive, centrifugal; polypropylene and stainless steel construction) at a velocity of approximately $5.0 \mathrm{ft} / \mathrm{s}(1.5 \mathrm{~m} / \mathrm{s})$. While the smalldiameter tubing used in these loops was about significantly thinner than the Type $\mathrm{M}$ in the large loops (i.e., wall thickness of about $0.013^{\prime \prime}$ or $0.033 \mathrm{~cm}$ versus $0.032^{\prime \prime}$ or $0.082 \mathrm{~cm}$ ), both were C12200 (phosphorous deoxidized) copper. And all copper tubing was deburred, rinsed with deionized water, allowed to dry, and weighed prior to assembling the pipeloops.

3.3. Data and Analyses. Changes in electrochemistry and chemistry were monitored in situ throughout testing, and copper tubes were subject to forensic analyses at the conclusion of the tests.

3.3.1. Corrosion Potential. Corrosion potential $\left(E_{\text {corr }}\right)$ was measured once per water change cycle for the large-scale tests, and two or three times per week for the small-scale tests. $E_{\text {corr }}$ was measured against $\mathrm{Ag}-\mathrm{AgCl}$ reference electrode using 


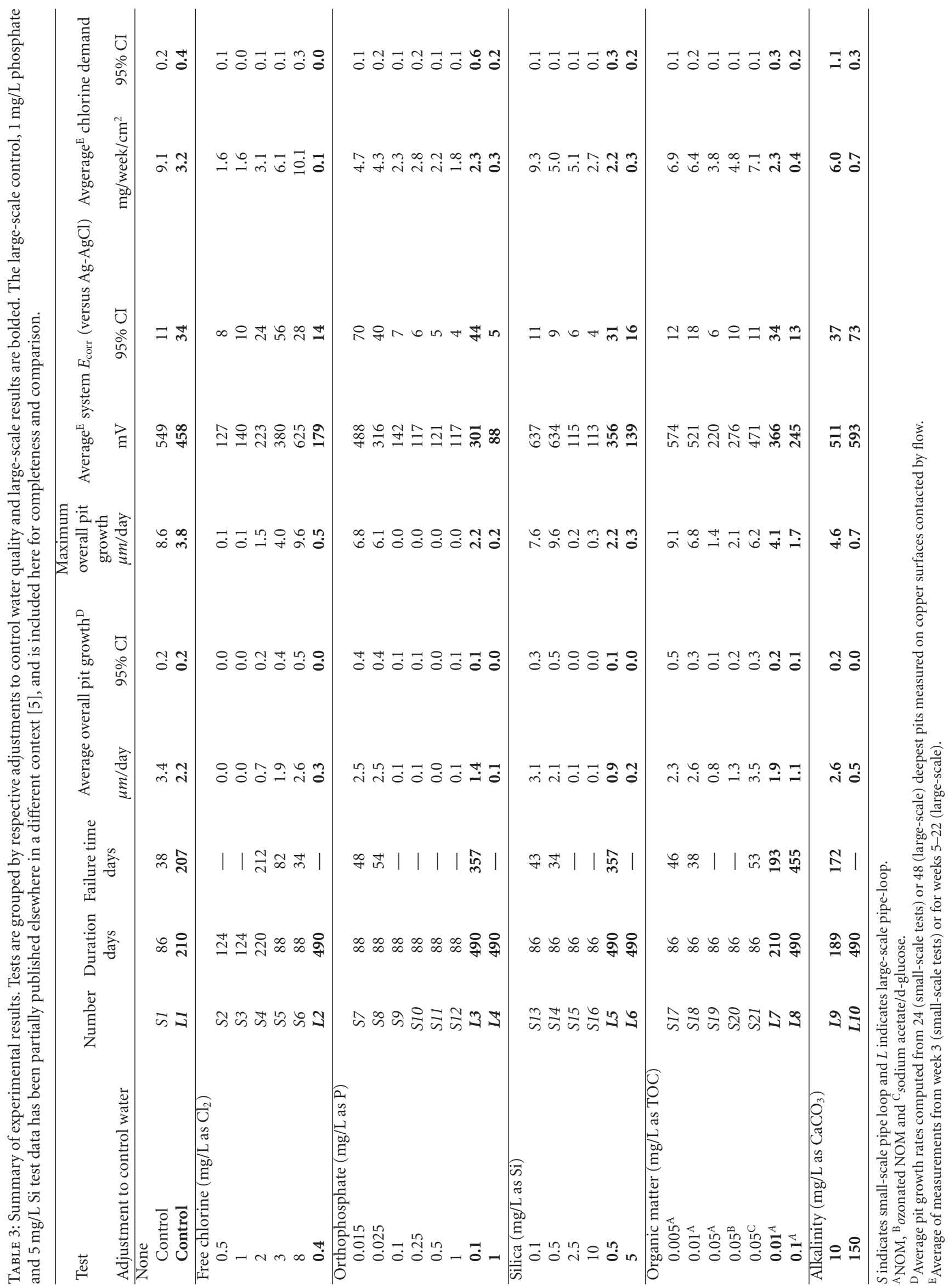


TABLE 4: Estimated pit initiation times and computed pit propagation rates based on $E_{\text {pit }}=325 \mathrm{mV}$ and $E_{\text {pit }}^{e}=260 \mathrm{mV}$ (versus Ag-AgCl). If $E_{\text {pit }}$ or $E_{\text {pit }}^{e}$ was not observed during test, pit initiation time could not be estimated. Tests are grouped by respective adjustments to control water quality and large-scale results are bolded.

\begin{tabular}{|c|c|c|c|c|c|c|}
\hline \multirow{3}{*}{ Test number } & & & \multicolumn{4}{|c|}{ Propagation rate $(\mu \mathrm{m} /$ day $)$} \\
\hline & \multicolumn{2}{|c|}{ Initiation time (days) } & \multicolumn{2}{|c|}{ Maximum } & \multicolumn{2}{|c|}{ Average } \\
\hline & $E_{\mathrm{pit}}$ & $E_{\mathrm{pit}}^{e}$ & $E_{\text {pit }}$ & $E_{\mathrm{pit}}^{e}$ & $E_{\text {pit }}$ & $E_{\mathrm{pit}}^{e}$ \\
\hline \multicolumn{7}{|l|}{ Control } \\
\hline S1 & 10 & 10 & 11.7 & 11.7 & 3.9 & 3.9 \\
\hline$L 1$ & 42 & 35 & 4.8 & 4.6 & 2.7 & 2.6 \\
\hline \multicolumn{7}{|l|}{ Chlorine } \\
\hline S2 & - & - & - & - & - & - \\
\hline S3 & - & - & - & - & - & - \\
\hline S4 & 141 & 97 & 8.0 & 3.8 & 3.3 & 1.7 \\
\hline S5 & 49 & 45 & 9.9 & 8.8 & 4.2 & 3.8 \\
\hline$S 6$ & 14 & 14 & 16.4 & 16.4 & 3.1 & 3.1 \\
\hline$L 2$ & 407 & 4.7 & 3.2 & 3.2 & 1.9 & 1.9 \\
\hline \multicolumn{7}{|l|}{ Phosphate } \\
\hline S7 & 28 & 25 & 16.4 & 14.2 & 3.7 & 3.5 \\
\hline S8 & 32 & 32 & 14.9 & 14.9 & 3.9 & 3.9 \\
\hline$S 9$ & - & - & - & - & - & - \\
\hline S10 & - & - & - & - & - & - \\
\hline$S 11$ & - & - & - & - & - & - \\
\hline$S 12$ & - & - & - & - & - & - \\
\hline$L 3$ & 77 & 77 & 2.8 & 2.8 & 1.7 & 1.7 \\
\hline$L 4$ & - & - & - & - & - & - \\
\hline \multicolumn{7}{|l|}{ Silica } \\
\hline S13 & 14 & 14 & 11.3 & 11.3 & 3.8 & 3.8 \\
\hline S14 & 16 & 16 & 18.2 & 18.2 & 2.6 & 2.6 \\
\hline S15 & - & - & - & - & - & - \\
\hline$S 16$ & - & - & - & - & - & - \\
\hline$L 5$ & 77 & 35 & 2.8 & 2.5 & 1.1 & 1.0 \\
\hline L6 & - & - & - & - & - & - \\
\hline \multicolumn{7}{|c|}{ Organic matter } \\
\hline S17 & 21 & 21 & 16.7 & 16.7 & 3.0 & 3.0 \\
\hline$S 18$ & 14 & 14 & 10.8 & 10.8 & 3.1 & 3.1 \\
\hline$S 19$ & 48 & 44 & 3.1 & 2.8 & 1.9 & 1.7 \\
\hline S2O & 28 & 26 & 3.2 & 3.1 & 1.9 & 1.8 \\
\hline$S 21$ & 20 & 20 & 8.7 & 8.7 & 4.5 & 4.5 \\
\hline$L 7$ & 70 & 29 & 6.5 & 4.9 & 2.8 & 2.2 \\
\hline$L 8$ & 217 & 71 & 3.3 & 2.1 & 1.9 & 1.2 \\
\hline \multicolumn{7}{|l|}{ Alkalinity } \\
\hline L9 & 35 & 15 & 5.8 & 5.1 & 3.1 & 2.8 \\
\hline$L 10$ & 35 & 15 & 0.7 & 0.7 & 0.5 & 0.5 \\
\hline
\end{tabular}

a Fluke 189 True RMS multimeter. In the convention utilized for this work, positive (i.e., noble) $E_{\text {corr }}$ values indicate an overall cathodic activity on the exposed copper.

3.3.2. Chlorine Demand. Since changes in chlorine concentration should be directly linked to the cathodic reaction rate (barring auto-decomposition or other minor reactions), the rate of chlorine consumption in the pipe loops can be correlated to the overall pitting rate [18]. A simple mass balance can be used to determine the rate of chlorine decay or, in tests where chlorine residual is maintained, the mass addition rate of chlorine needed to maintain a target residual. 


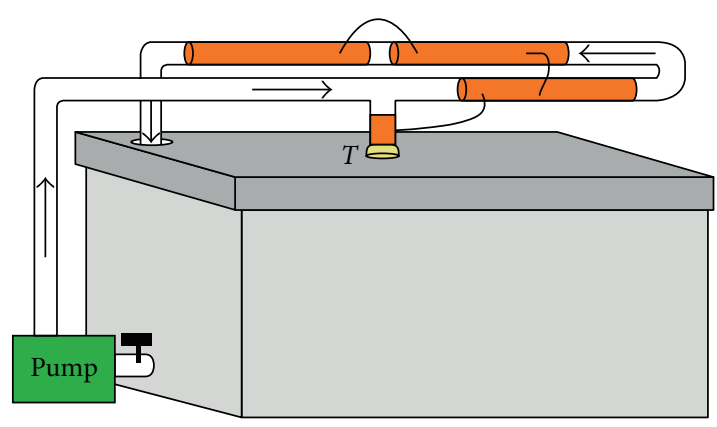

(a)

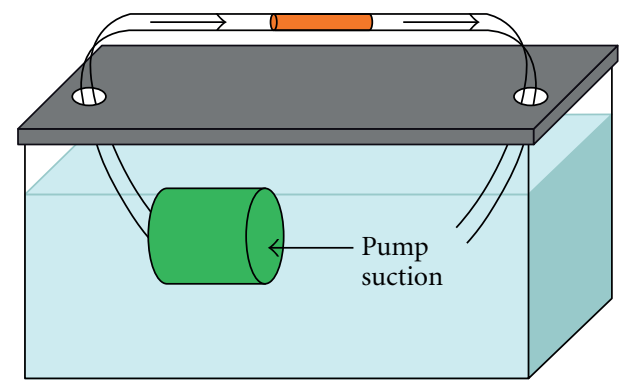

(b)

FIGURE 2: Large and small pipe-loop apparatuses; flow direction is indicated by arrows.

The latter has been termed "chlorine demand" and shown to be useful in monitoring copper pitting in high $\mathrm{pH}$, low alkalinity water [5].

In this work, chlorine demand $\left(\mathrm{mg} /\right.$ week $\left./ \mathrm{cm}^{2}\right)$ was determined for each test once per water change cycle, using (1)

$$
\text { chlorine demand }=\frac{V_{B}\left(C_{B i}-C_{B f}\right)+V_{F} C_{F}+V_{S} C_{S}}{t(A)},
$$

where $t$ is elapsed time (weeks), $A$ is copper surface area exposed to water $\left(\mathrm{cm}^{2}\right), V_{B}$ is bulk water volume $(\mathrm{L}), C_{B i}$ and $C_{B f}$ are initial and final bulk chlorine concentrations $(\mathrm{mg} / \mathrm{L})$, $V_{F}$ and $C_{F}$ are volume $(\mathrm{L})$ and chlorine concentration $(\mathrm{mg} / \mathrm{L})$ of feed solution automatically added, and $V_{S}$ and $C_{S}$ are volume (L) and chlorine concentration $(\mathrm{mg} / \mathrm{L})$ of stock solution manually added.

3.3.3. Forensic Analyses. Forensic examination of copper tubes included quantitative characterization of pit depths and growth rates, and qualitative characterization of corrosion scales. At the conclusion of tests, tubes were removed from pipe loops and allowed to dry prior to being cut lengthwise and cleaned. Corrosion scales were removed chemically using household copper cleaner from tubes in small-scale tests; scales were removed mechanically using a Dremel tool with a fine-bristle steel brush in large-scale tests. Neither method significantly removed metallic copper from the tubes, which was confirmed by testing both cleaning protocols on new, uncorroded copper samples. A digital, fine-tipped Mitutoyo micrometer ( $0.001 \mathrm{~mm}$ resolution) was used to measure tube-wall thicknesses as guided by ASTM G46 [32].

Maximum and average overall pit growth rates ( $\mu \mathrm{m} /$ day) were computed to determine the rapidity at which pits penetrated through copper in each test using (2) and (3), respectively

$$
\begin{gathered}
\text { Maximum pit growth rate }=\frac{\mathrm{MPD}}{X} \text { or } \frac{\mathrm{MPD}}{Y}, \\
\text { average overall pit growth rate }=\frac{\mathrm{APD}}{Y},
\end{gathered}
$$

where MPD and APD are the maximum and average pit depths $(\mu \mathrm{m})$ measured in a given test, $X$ is the failure time (days) (i.e., the time-to-first pinhole leak failure, if one occurred), and $Y$ is the total test duration (days). In tests where at least one pinhole leak occurred, the fastest growing pit could only grow through the copper from the start of the test until the failure time, so the maximum pit growth rate was calculated using $X$; in tests where a leak did not occur, this pit was allowed to grow throughout the test, so the rate was calculated using $Y$.

\section{Results}

Very large differences in time-to-failure (i.e., leak), trends in $E_{\text {corr }}$, chlorine demand, and other factors were observed during the large- and small-scale loops under the various test conditions (Table 3). Many tests (e.g., control) ended with either fully penetrating pinhole leaks or very severe pitting, but others (e.g., with high phosphate dosages) produced no detectable pitting whatsoever (Figure 3 ). The sections that follow describe trends in failure times, overall pit growth rates, and $E_{\text {corr }}$ data, followed by presentation of pit initiation and propagation results based on interpretation of $E_{\text {corr }}$ rise data.

4.1. Failure Times and Overall Pit Growth Rates. The control condition (no inhibitor) was amongst the fastest to produce pinhole leaks; failure times for the large- and small-scale control tests occurred at 207 and 38 days, respectively (Table 3). Tests with reduced alkalinity, or dosing of low levels of phosphate, silica, or NOM also produced pinholes, generally within the same time frame as the control tests. In contrast, tests with higher concentrations of inhibitors did not produce leaks.

The time-to-failure was found to be inversely related to free chlorine concentration in the small-scale tests with residuals of $2 \mathrm{mg} / \mathrm{L}$ or higher, but neither pinhole failures nor pitting occurred at lower residuals (i.e., 1 or $0.5 \mathrm{mg} / \mathrm{L}$ ) within the 140-day tests. This does not mean that chlorine levels of $1 \mathrm{mg} / \mathrm{L}$ or less should be considered "safe" under continuous flow conditions; in fact, just $0.4 \mathrm{mg} / \mathrm{L}$ chlorine caused some deep pits to form during a 490 day (1.3 year) large-scale test. 

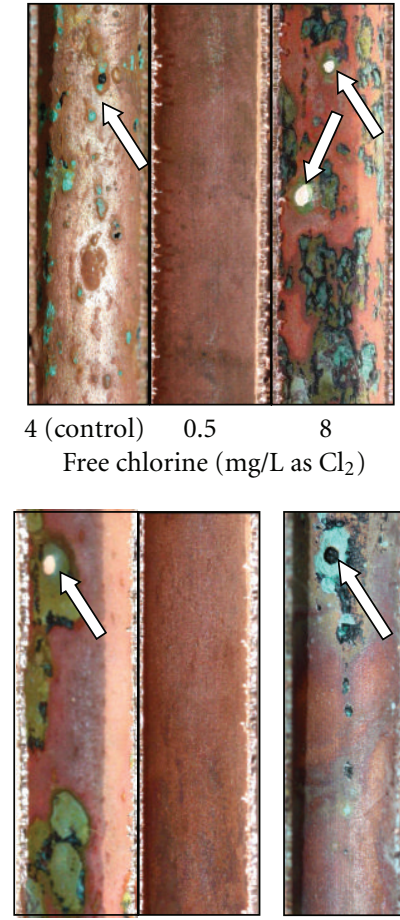

0.015

Phosphate (mg/L as $\mathrm{P})$

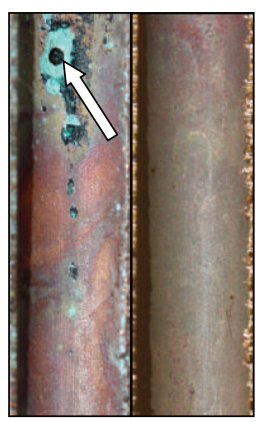

0.05

Silica $(\mathrm{mg} / \mathrm{L}$ as $\mathrm{Si})$

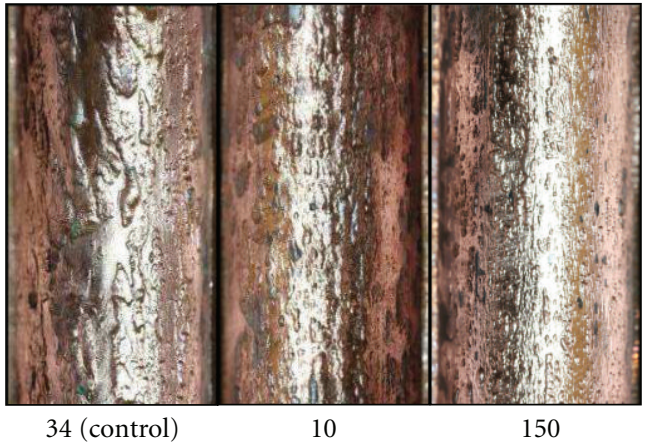

Alkalinity $\left(\mathrm{mg} / \mathrm{L}\right.$ as $\left.\mathrm{CaCO}_{3}\right)$

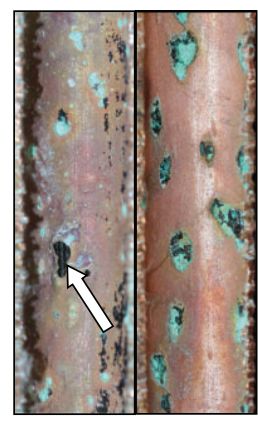

$0.005^{\mathrm{A}} \quad 0.05^{\mathrm{A}}$

Organic matter

$(\mathrm{mg} / \mathrm{L}$ as TOC)

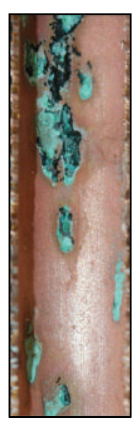

$0.05^{\mathrm{B}}$

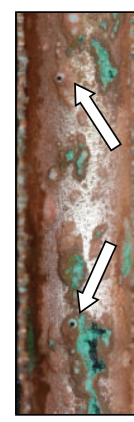

$0.05^{\mathrm{C}}$

Figure 3: Representative photographs of copper from selected tests following scale removal. Photos are grouped by respective adjustments to control water quality ( ${ }^{\mathrm{A}} \mathrm{NOM},{ }^{\mathrm{B}}$ ozonated NOM, ${ }^{\mathrm{C}}$ sodium acetate/d-glucose), and arrows indicate some of the pinhole leaks that formed during testing. All photos show copper from small-scale tests, except for those in the variable alkalinity group.

These results strongly suggest that, given long enough, even low levels of chlorine can cause pitting.

On the basis of failure times, test durations, and final pit depths, overall maximum and average pit growth rates (Table 3) were found to increase with increasing chlorine, and decrease with increasing phosphate, silica, NOM, or alkalinity (e.g., Figure 4, top). At small-scale, the fastest average growth rates occurred in the control and $0.05 \mathrm{mg} / \mathrm{L}$ acetate and glucose tests, while the fastest maximum growth rates (i.e., fastest failure time) occurred in the $8 \mathrm{mg} / \mathrm{L}$ chlorine and $0.5 \mathrm{mg} / \mathrm{L}$ silica (as Si) tests. At large scale, the fastest maximum and average rates occurred in the $10 \mathrm{mg} / \mathrm{L}$ alkalinity (as $\mathrm{CaCO}_{3}$ ) test-and the next fastest were in the control and $0.01 \mathrm{mg} / \mathrm{L} \mathrm{NOM}$ (as TOC). At $150 \mathrm{mg} / \mathrm{L}$ alkalinity, significant pitting did occur, although overall pit growth rates were markedly reduced (e.g., the average growth rate was only $20 \%$ of that in the control test). This is consistent with hypotheses of Lytle and Schock [3] and Cong et al. [4] regarding benefits of higher alkalinity.

At higher dosages (i.e., $>0.025 \mathrm{mg} / \mathrm{L}$ at small-scale and $>0.1 \mathrm{mg} / \mathrm{L}$ at large scale), pitting was completely inhibited by phosphate such that overall pit growth rates were negligible. A similar case was observed for silica, which inhibited all pitting in the small-scale tests with $>0.5 \mathrm{mg} / \mathrm{L}$ (as $\mathrm{Si}$ ) and only allowed minor pitting in the large-scale test with $5 \mathrm{mg} / \mathrm{L}$. Although increasing NOM decreased pit growth rates, no level of NOM was tested that completely inhibited pitting. Furthermore, results clearly demonstrated that the type of organic matter is critical to the efficacy of pitting inhibition. As compared to the control (i.e., no organic matter added), $0.05 \mathrm{mg} / \mathrm{L}$ unozonated NOM in the small-scale test resulted in more than $75 \%$ deceleration of the average pit growth rate, whereas an equal dose of ozonated NOM only resulted in about $60 \%$ deceleration; while an equal dose of the acetate and glucose mixture did not decelerate the pitting rate at all. Thus, the form of the organic matter (i.e., type of NOM) present is a critical factor in natural inhibition of copper pitting.

4.2. $E_{\text {corr }}$ Data. Generally speaking, the overall pit growth rates correlated well with average system $E_{\text {corr }}$ (i.e., rest potential of all copper surfaces exposed to test water versus $\mathrm{Ag}-\mathrm{AgCl}$ reference) (Figure 5) and chlorine demand (Table 3), except for a few isolated cases. For example, the high alkalinity condition consistently had high $E_{\text {corr }}$ but produced relatively shallow pits within the test duration, albeit at a very high density (see Figure 3 ). This might indicate that although many pits were being initiated (as suggested by the high $E_{\text {corr }}$ and confirmed by later visual observation), pits did not propagate rapidly. It is speculated that this might be due to formation of protective malachite scales on the surface, higher $\mathrm{pH}$ in the pit due to buffering capacity of bicarbonate, or other factors. 

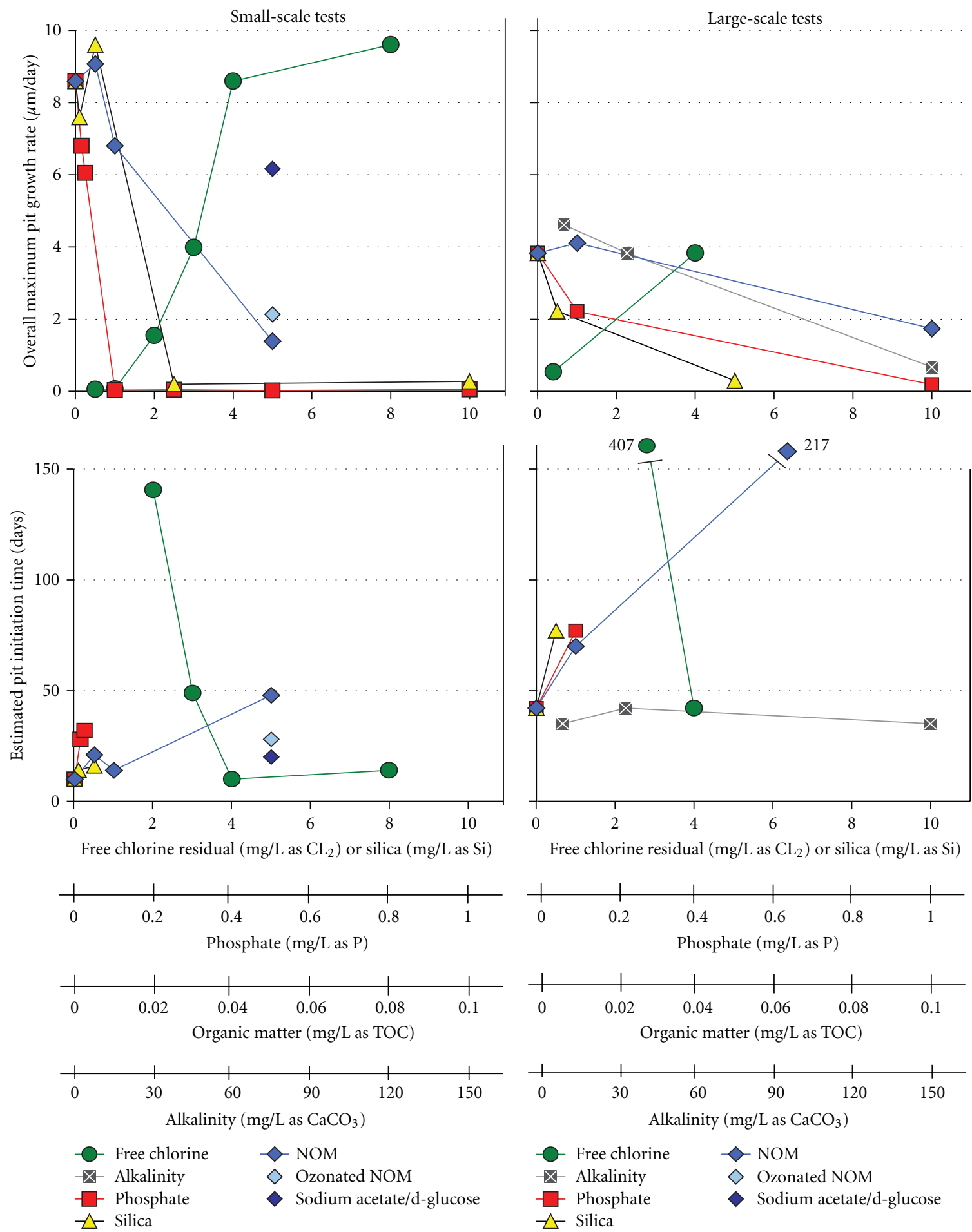

(a)
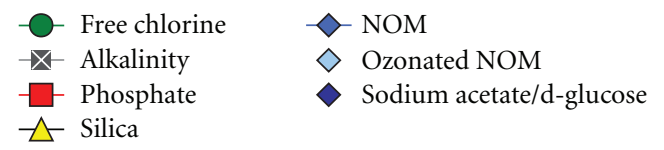

(b)

FIGURE 4: Overall maximum pit growth rate (top) and estimated pit initiation time (bottom) versus tested constituent concentrations for small- (a) and large-scale tests (b). Initiation times based on $E_{\text {pit }}=325 \mathrm{mV}$ (versus Ag-AgCl); values not determined in tests where $E_{\text {pit }}$ not observed.

4.3. Pit Initiation and Propagation. In the preceding sections, no attempt was made to distinguish between pit initiation and propagation phases. However, it is likely that the rates of pit initiation and propagation are a function of water chemistry. Assuming the conventional electrochemical interpretation is correct-that a critical potential must be reached prior to the onset of copper pitting in aggressive waters like those tested in this work-the time-to-pit initiation and 


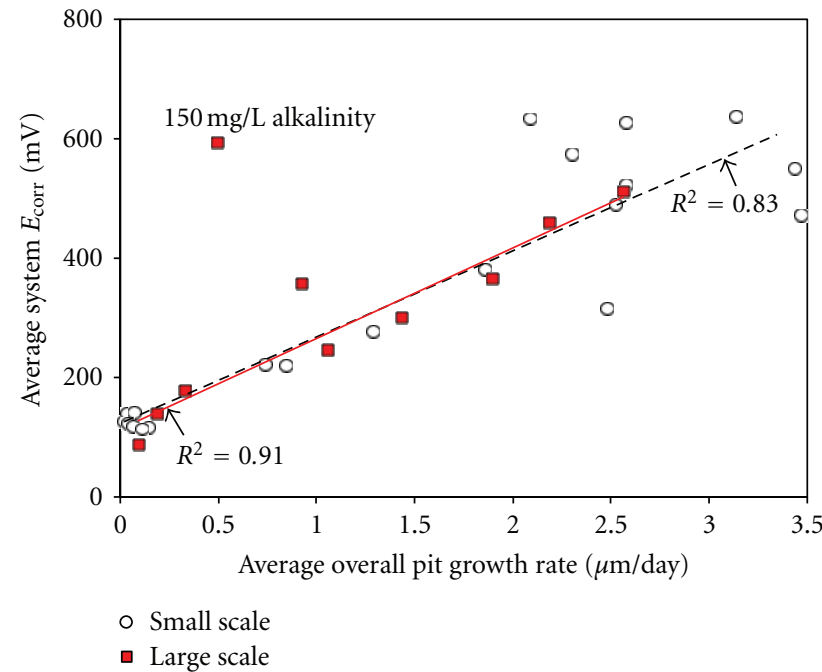

FIGURE 5: Average system $E_{\text {corr }}$ versus overall pit growth rate for all tests. The $150 \mathrm{mg} / \mathrm{L}$ alkalinity condition did not follow the same trend as other data and is not included in the computed $R^{2}$ value for the large-scale tests.

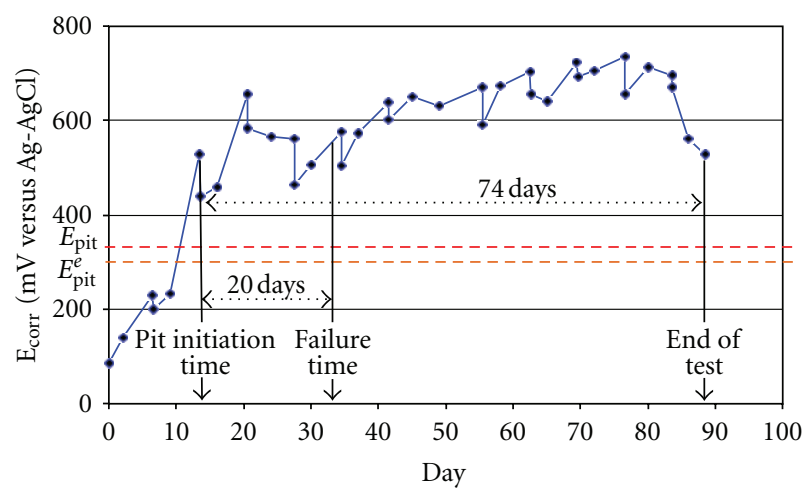

FIGURE 6: $E_{\text {corr }}$ versus time for small-scale test with free chlorine residual adjusted to $8 \mathrm{mg} / \mathrm{L}$. Using $E_{\text {pit }}=325 \mathrm{mV}$ (versus $\mathrm{Ag}-\mathrm{AgCl}$ ), the pit initiation time (14 days) and the relative times available for maximum (20 days) and average (74 days) pit propagation were estimated. In this test, using $E_{\text {pit }}^{e}$ instead of $E_{\text {pit }}$ did not change estimated initiation time and propagation rates since $E_{\text {corr }}$ rose above both values between the measurements on days 11 and 14 .

the duration of pit propagation during each experiment can be estimated from simple plots of $E_{\text {corr }}$ versus time for each test (e.g., Figure 6) It is recognized that there may well be some incubation period between the time that $E_{\text {corr }}$ rises above $E_{\mathrm{pit}}$ and the time that pits are actually initiated. However, because methods are not available to quantify this time period, and because electrochemical measurements were collected at regular intervals but not continuously, pit initiation times determined in this work are estimations and are only intended for use in comparing tested conditions to one another.

To illustrate, the critical potentials for analyses in this work were selected by interpolating results from recent works by Cong et al. $[4,14]$. In one study, $C V$ was used to define $E_{\text {pit }}$ at several pHs (i.e., from 7.4 to 11 ) in a similar water quality to that used here (i.e., control water in this study without free chlorine) [4]. By interpolating results from that study, $E_{\text {pit }}$ at pH 9.2 is approximately $325 \mathrm{mV}$ (versus $\mathrm{Ag}-\mathrm{AgCl}$ ). However, in a later study, CMEAs were used to investigate pitting across a similar $\mathrm{pH}$ range (i.e., from 7 to 10) in the same water with free chlorine and aluminum solids, and results indicated that pitting can actually occur at somewhat lower potentials than the previously defined $E_{\text {pit }}$ values [14]. Consequently, an effective $E_{\text {pit }}$ (termed $E_{\text {pit }}^{e}$ herein) at pH 9.2 was found to be about $260 \mathrm{mV}$ (versus $\mathrm{Ag}-\mathrm{AgCl}$ ).

For each test in the current work that produced significant pitting, $E_{\text {corr }}$ was indeed observed to rise to and, at least temporarily, remain above these approximated $E_{\mathrm{pit}}$ and $E_{\mathrm{pit}}^{e}$ values. If the time of the first measurement at or above one of these values is considered to be the pit initiation time, maximum and average pit propagation rates (i.e., rate of pit penetration through the copper tube wall) can be calculated based on the time elapsed from initiation to either the time of failure or end of a test, respectively. Both $E_{\mathrm{pit}}$ and $E_{\mathrm{pit}}^{e}$ were used to estimate pit initiation times and propagation rates in this work, but since most tests that produced pitting exhibited very rapid $E_{\text {corr }}$ rise (e.g., see Figure 6), results based on $E_{\text {pit }}$ were generally similar to those based on $E_{\text {pit }}^{e}$ (Table 4). For simplicity, only the analyses based on $E_{\text {pit }}$ will be discussed in detail from here.

4.3.1. Pit Initiation Times. Many conditions (e.g., $8 \mathrm{mg} / \mathrm{L}$ chlorine at small scale) that appear to have initiated pits quickly also tended to have rapid overall pit growth rates (Figure 4) and failure times. In contrast, conditions that had initially appeared to have relatively slow pit growth rates (e.g., $0.4 \mathrm{mg} / \mathrm{L}$ chlorine) had long delays to pit initiation.

At the lowest chlorine levels in the small-scale tests (i.e., 0.5 and $1 \mathrm{mg} / \mathrm{L}$ ), and the highest dosages of phosphate (i.e., $>0.25 \mathrm{mg} / \mathrm{L}$ ) and silica (i.e., $>2.5 \mathrm{mg} / \mathrm{L}$ ) in both large and small tests, $E_{\text {corr }}$ was never observed to reach or exceed the critical $325 \mathrm{mV}$ value, and pits were not observed on copper from these conditions. The exception was some shallow pits in the $5 \mathrm{mg} / \mathrm{L}$ silica test at large scale (i.e., $<20 \%$ penetration through the pipe wall after 490 days). The highest $E_{\text {corr }}$ measured in that test was approximately $240 \mathrm{mV}$, which is very close to the defined $E_{\text {pit }}^{e}$ condition. The maximum $E_{\text {corr }}$ measured in the $2.5 \mathrm{mg} / \mathrm{L}$ silica small-scale test $(2-3$ measurements per week) was about $245 \mathrm{mV}$, but no pits formed in that condition.

Even small amounts of (unozonated) NOM appear to have delayed pit initiation substantially. As compared to the control condition, $0.1 \mathrm{mg} / \mathrm{L} \mathrm{NOM}$ in the large-scale test delayed the estimated time to pit initiation by a factor of about four, and just $0.05 \mathrm{mg} / \mathrm{L} \mathrm{NOM}$ in the small test delayed the initiation time by a factor of five. However, an equal dosage of ozonated NOM or the acetate and glucose mixture delayed the initiation time by only a factor of $2-3$, respectively.

It was observed that $E_{\text {corr }}$ rise was generally more rapid, and thus pits apparently initiated more quickly, in the smallscale tests than in large scale for identical or similar water quality conditions (e.g., 10 versus 42 days for control). 
This discrepancy is most likely related to differences in the pipe loop apparatuses (e.g., exposed copper surface area to bulk water volume ratio), operating conditions (e.g., flow velocity), and/or water change schedules. It is noteworthy that some test conditions that eventually caused pitting at large-scale had small-scale analogues that were not observed to produce pits. For instance, the large pipe loop with $0.4 \mathrm{mg} / \mathrm{L}$ free chlorine formed pits that penetrated nearly $20 \%$ of the tube wall and had an estimated pit initiation time of over 400 days; whereas pitting did not occur in the 0.5 and $1 \mathrm{mg} / \mathrm{L}$ tests in the small loops, and $E_{\text {corr }}$ also did not exceed $E_{\text {pit }}$. It is possible that if these small-scale tests been continued, pits might have eventually been initiated and propagated, as $E_{\text {corr }}$ was indeed rising towards the end of the $1 \mathrm{mg} / \mathrm{L}$ test duration and reached a maximum value of $248 \mathrm{mV}$ just 20 days before the test concluded.

\subsubsection{Pit Propagation Rates and Chlorine Demand. Pit prop-} agation rates and chlorine demand were also a strong function of tested water conditions (Figure 7). For tests with variable alkalinity Figure 7(a) or with added silica Figure 7(b), phosphate Figure 7(c) or organic matter Figure 7(d), average chlorine demand was well correlated with computed average pit propagation rates (i.e., the penetration rate of the average pit from the estimated pit initiation time until the conclusion of a test). However, this was not the case for tests with variable free chlorine residuals Figure 7(a), probably due to auto-decomposition kinetics of chlorine (i.e., the reaction is nonzero order, so the rate of chlorine decay is dependent on chlorine concentration).

Interestingly, although the concentration of chlorine seems to have significantly influenced pit initiation time, it does not appear to have greatly influenced pit propagation rates. Of the small-scale tests with variable chlorine that produced pitting (i.e., $2-8 \mathrm{mg} / \mathrm{L}$ chlorine tests), average pit propagation rates only varied by about $25 \%$ (based on $E_{\text {pit }}$ $=325 \mathrm{mV})$; at large-scale, the rate of the $0.4 \mathrm{mg} / \mathrm{L}$ chlorine test was only about $30 \%$ lower than the control $(4 \mathrm{mg} / \mathrm{L}$ chlorine). Furthermore, the maximum pit propagation rates (i.e., the penetration rate of the fastest growing pit) also appear to have been very similar, which is fascinating considering the dramatically different pit initiation and failure times between tests with varying chlorine levels. For instance, while the time-to-failure for the 2 and $8 \mathrm{mg} / \mathrm{L}$ chlorine test was separated by a factor of roughly 6 (i.e., 212 versus 34 days), the calculated maximum pit propagation rate only differed by a factor of 2 (i.e., 16.4 versus $8.0 \mu \mathrm{m} /$ day). This finding suggests that in premise plumbing systems where water flow is not continuous and chlorine can decay rapidly during stagnation, the critical factor in the time to pinhole leak failure may be more dependent on the rate of pit initiation than on the rate of propagation. Under less extreme conditions known to reduce the rate of $E_{\text {corr }}$ rise (e.g., typical intermittent flow experienced in premise plumbing systems) (e.g., [18]), the relative importance of pit initiation is expected to become even more critical. This might explain why, in some real systems that have experienced outbreaks of pitting, much higher incidence of pinholes have been reported near the water treatment facility where levels of chlorine are much higher [33].

At very low dosages of phosphate (i.e., 0.015 and $0.025 \mathrm{mg} / \mathrm{L}$ ), silica (i.e., $0.5 \mathrm{mg} / \mathrm{L}$ ), and NOM (i.e., $0.005 \mathrm{mg} / \mathrm{L}$ ), maximum pit propagation rates in the small-scale tests were computed to be $27-56 \%$ higher than in the control condition. This supports the hypothesis that these constituents may function, at least in part, as anodic pitting inhibitors, reducing the overall number of pits and thus focusing the cathodic reaction on more rapid attack at fewer anode sites. There were indeed proportionally fewer deep pits (and more shallow pits) in these very low-dose inhibitor tests than in the control, which exhibited more uniform pit depths. To illustrate, only about $25-35 \%$ of measured pits penetrated more than $80 \%$ of the pipe wall in the very low-dose inhibitor tests, while $75 \%$ of the pits did in the control test. At large scale, a similar observation was also made between the $0.1 \mathrm{mg} / \mathrm{L} \mathrm{NOM}$ and control tests.

At higher dosages of phosphate, silica, and NOM, computed maximum and average pit propagation rates were reduced significantly_if pits were formed at all. Chlorine demand data indicates that at higher dosages, these constituents provided cathodic inhibition of pitting in addition to any anodic inhibition that occurred. Not only was the average chlorine demand lower in the tests with higher inhibitor dosages (Figure 7) but so was the initial chlorine demand measured after just 72 hours (not shown). This suggests that the inhibitors were directly preventing the chlorine reduction (i.e., cathodic) reaction over the duration of the tests. Mechanistically, phosphate, silica and/or NOM inhibitors may form a protective film or scale that hinders chlorine interaction with the copper surface. Because each of these species is anionic at high $\mathrm{pH}$-as is hypochlorite $\left(\mathrm{OCl}^{-}\right)$- it is also possible that they are sorbing to surfaces to create net anionic charge, which effectively repels hypochlorite and reduces chlorine-copper surface reactions.

Although ozonated NOM did not appear to delay pit initiation to the same degree as un-ozonated NOM, its effects on pit propagation rates were nearly identical to those of unozonated NOM. Both reduced the average propagation rate by about $50 \%$ (versus control). In contrast, the acetate and glucose mixture did not reduce the average pit propagation rate whatsoever. This suggests that certain fractions of organic matter present in potable water may have different dose-response behavior.

Increased alkalinity also appears to have reduced pit propagation rates, which is consistent with the idea that pits grew very slowly (or stopped growing soon after initiation) in this test, despite probably being initiated at similar times as in the control. The relatively low average chlorine demand in this test (Figure 7) corresponds to a reduced rate of the cathodic reaction, which in turn reduced the rate of pit growth.

\section{Discussion}

5.1. Free Chlorine. In distribution systems with water characterized by high $\mathrm{pH}$ and low alkalinity, decreasing free 


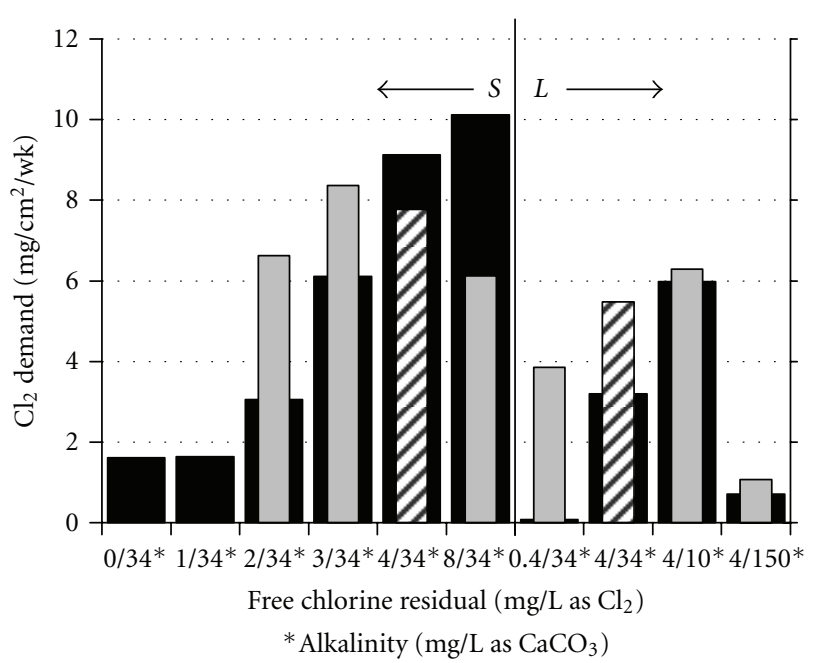

(a)

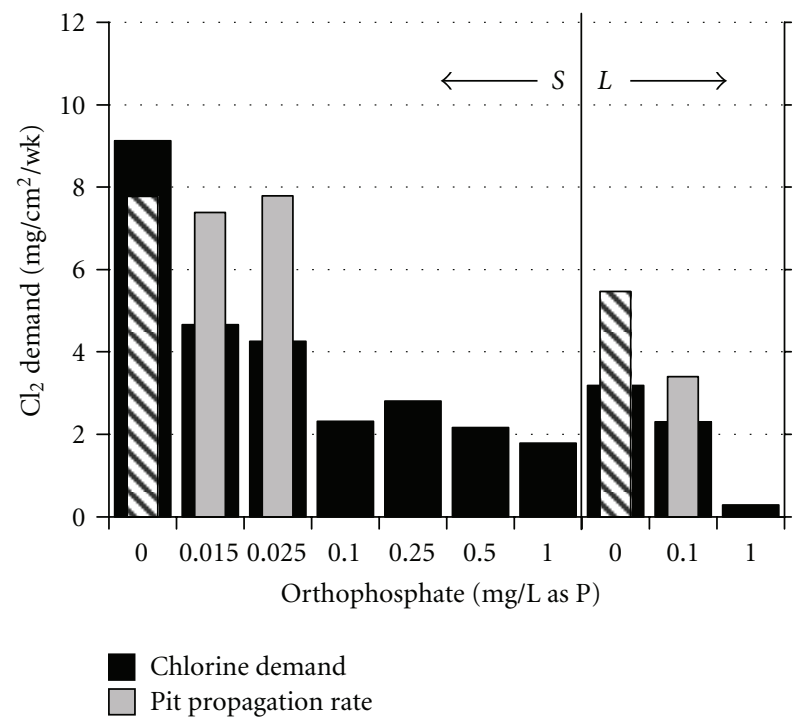

(c)

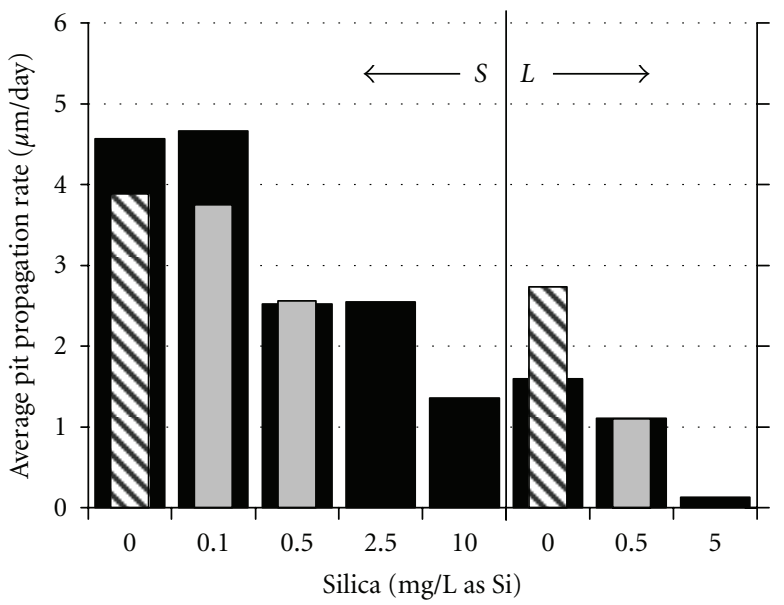

(b)

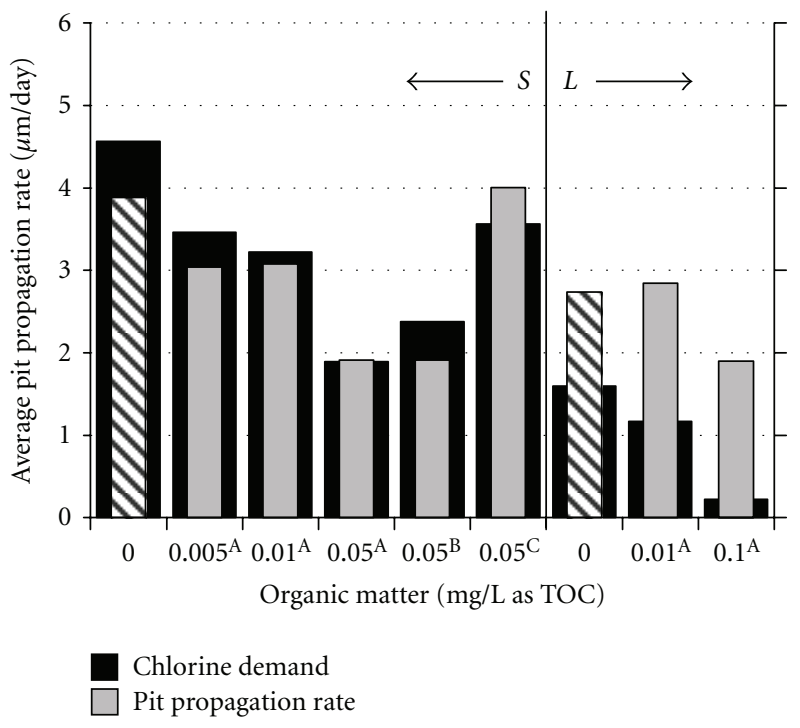

(d)

Figure 7: Chlorine demand (dark shading) and computed average pit propagation rates (light shading) based on $E_{\text {pit }}=325 \mathrm{mV}$ (versus Ag$\mathrm{AgCl})$. No propagation rate is shown for tests in which $E_{\text {pit }}$ was not observed. Conditions are grouped by respective changes to the control water quality ( ${ }^{\mathrm{A}} \mathrm{NOM},{ }^{\mathrm{B}}$ Ozonated NOM, ${ }^{\mathrm{C}}$ sodium acetate/d-glucose), and the control tests are shown with hash marks in each grouping. $\mathrm{S}$ and L indicate small- and large-scale tests, respectively.

chlorine residual across the system (e.g., reduced dosing at the treatment facility perhaps with use of booster stations to achieve adequate disinfection) would probably dramatically reduce but not eliminate pitting attack. Based on results of this work, a "safe" upper limit on free chlorine cannot be defined with certainty, but if such a limit does exist, it would clearly be less than $0.4 \mathrm{mg} / \mathrm{L}$ (Table 1 ). Since most test work to date has been conducted at continuous flow $[3,5,16]$ — which markedly increases pitting [2] but is only representative of specific sections of premise plumbing systems (e.g., hot water recirculation lines)-more research is needed to investigate dose-response effects of chlorine at a less frequent flow typical of premise plumbing. It is quite possible that somewhat higher chlorine residuals under intermittent flow conditions would indeed not initiate pitting for some period of time-perhaps the lifetime of a copper plumbing system. It should be noted that, to date, pitting has not been shown to initiate without free chlorine in high $\mathrm{pH}$, low alkalinity waters, and confirmation experiments may not be possible given that much longer test durations would be required than those presented here (i.e., decades versus 1.3 years).

The current findings are consistent with some prior observations with respect to the effects of free chlorine residual on copper pitting. Lytle and Schock demonstrated that free chlorine residuals of just $0.3-0.8 \mathrm{mg} / \mathrm{L}$ could cause some pits in high $\mathrm{pH}$ (i.e., $\sim 9$ ) and low alkalinity (i.e., $\sim 40-80 \mathrm{mg} / \mathrm{L}$ as $\mathrm{CaCO}_{3}$ ) waters in continuously recirculating pipe loops at relatively low flow velocity (i.e., $1.1 \mathrm{ft} / \mathrm{s}$ ) over a 99-day experimental time [3]. These pits 
were relatively shallow compared to those produced in the current work, with the maximum reported penetration of $0.2 \mathrm{~mm}$. Lytle and Nadagouda reported that an Ohio community experiencing copper pitting problems in high $\mathrm{pH}$ (i.e., $\sim 8.3$ ) and low alkalinity (i.e., $\sim 40 \mathrm{mg} / \mathrm{L}$ ) waters had a free chlorine residual of only about $0.5 \mathrm{mg} / \mathrm{L}$; the water also had a natural silica concentration of about $\sim 4.7 \mathrm{mg} / \mathrm{L}$ (as $\mathrm{Si}$ ) [16]. Interestingly, pitting was limited to cold water lines and measured free chlorine in hot water lines was less than in cold (i.e., 0.3 versus $0.5 \mathrm{mg} / \mathrm{L}$ ). Additionally, copper pinholes were reported to occur roughly 4-6 years after plumbing installation. In other instances, copper pinholes developed much faster when free chlorine residuals were higher [1]. Overall, on the basis of free chlorine residual, the above observations are not inconsistent with the present findings that higher chlorine can initiate pitting more quickly than lower chlorine.

Using CMEAs in relatively short-term experiments, Cong and Scully determined that chlorine levels as low as $1 \mathrm{mg} / \mathrm{L}$ could cause copper pitting (as indicated electrochemically) in a similar water quality as that used in the present work (i.e., control water with aluminum solids added); at lower $\mathrm{pH}$, more chlorine was required to induce pitting [21]. They also showed that pitting severity (based on a computed "pitting factor" and maximum total anodic charge) increased with chlorine concentration, which may have been partially related to the short duration of the experiments ( 6 days) or the near stagnant conditions (i.e., chlorine levels depleted more rapidly at copper surface for low chlorine residual tests). The authors acknowledged that differing flow conditions and exposure times might alter their predictions. Thus, at higher flow and with longer exposure time, the level of chlorine needed to induce pitting in the CMEA experiment may be much lower. The impacts of exposure time illustrated in the present work are certainly consistent with this hypothesis, and the tendency of increased flow velocity and frequency to increase pitting propensity have been reported elsewhere $[2,7,18]$.

5.2. Alkalinity. Unlike free chlorine, the primary effect of alkalinity appeared to be on pit propagation rates. Large increases in alkalinity (i.e., 150 versus $34 \mathrm{mg} / \mathrm{L}$ as $\mathrm{CaCO}_{3}$ in the control) slowed pit propagation-consistent with qualitative observations of Lytle and Schock [3] —but severe pitting occurred during the 490-day test duration nonetheless; lower alkalinity (i.e., $10 \mathrm{mg} / \mathrm{L}$ versus the control) accelerated pit propagation. Alkalinity seems to have had no significant influence on pit initiation time, so it is likely that pits would form in high $\mathrm{pH}$, higher alkalinity waters (i.e., similar to the high alkalinity condition presented here) even at relatively low chlorine residuals. However, further research is warranted to elucidate the competing effects of chlorine and alkalinity over a range of $\mathrm{pH}$ values. It is possible that some combinations of these constituents exist that will allow pits to develop, but not grow at any appreciable rate as to cause pinhole leaks.
5.3. Phosphate and Silica. Overall, for pitting caused by high $\mathrm{pH}$, free chlorine, and low alkalinity, phosphate or silica inhibitor dosing was confirmed to be a relatively effective mitigation strategy, as has been reported elsewhere [3, 5-7]. At sufficient dosages, these constituents might completely inhibit pitting by hindering the cathodic reaction (i.e., chlorine reduction) and preventing initiation of pits. If pits do initiate (or initiated prior to inhibitor dosing), phosphate or silica may reduce pit propagation rates or perhaps stop propagation entirely. However, it is difficult to precisely predict what the threshold dosages may be, due to discrepancies between small- and large-scale tests. For example, just $0.1 \mathrm{mg} / \mathrm{L}$ phosphate was sufficient to completely inhibit pitting in the small pipe loop (86 day test), but pits and ultimately pinholes eventually developed in the large loop with the same phosphate dose (490 day test).

In the case of silica, there does seem to be a minimum dosage that had virtually no effect on pitting (i.e., $0.1 \mathrm{mg} / \mathrm{L}$ as $\mathrm{Si}$ in the current work). Practically, this could also be the case for phosphate, and may explain why, despite naturally occurring levels of these constituents or very low doses used as inhibitors at some utilities, consumers in such systems experience copper pitting incidents. This was clearly the case for an Ohio community investigated by Lytle and Nadagouda, which experienced copper pitting problems despite a natural silica level in water of about $4.7 \mathrm{mg} / \mathrm{L}$ (as Si) [16]. Another example is a Maryland distribution system that has been plagued by copper pinholes, attributed to high $\mathrm{pH}$, free chlorine, and aluminum solids and which also has a natural silica level of about 3$3.5 \mathrm{mg} / \mathrm{L}$ (as Si) [34]. Alternatively, mechanisms initiating and propagating pitting during typical intermittent flow events could differ somewhat from results obtained during continuous flow testing. For example, prior work under conditions more representative of flow in premise plumbing suggested that aluminum solids would markedly increase pitting $[2,18]$, but later work that has been conducted under continuous flow has indicated the aluminum solids are not necessary and may even have an inhibiting effect $[3,8,35]$.

5.4. Field Confirmation. The authors were involved in a full-scale case study in the Maryland distribution system mentioned above. This system began experiencing significantly increased volumes of pinhole leak reports in the late 1990s (Figure 8), which prompted several studies into the extent and cause of the leak problem (e.g., see [1, $3]$ ). Following some successful water quality modifications including a slight reduction in finished $\mathrm{pH}$ and aluminum concentration, phosphate corrosion inhibitors were introduced to the treatment process in late 2003, and dramatic overall reductions in pinhole failures were realized (based on customer reports) $[29,36]$. The authors also implemented phosphate dosing in two Tennessee distribution systems, where copper pinholes were believed to be caused by high $\mathrm{pH}$ and high free chlorine residual. Introduction of orthoor ortho/polyphosphate blends (in combination with $\mathrm{pH}$ 


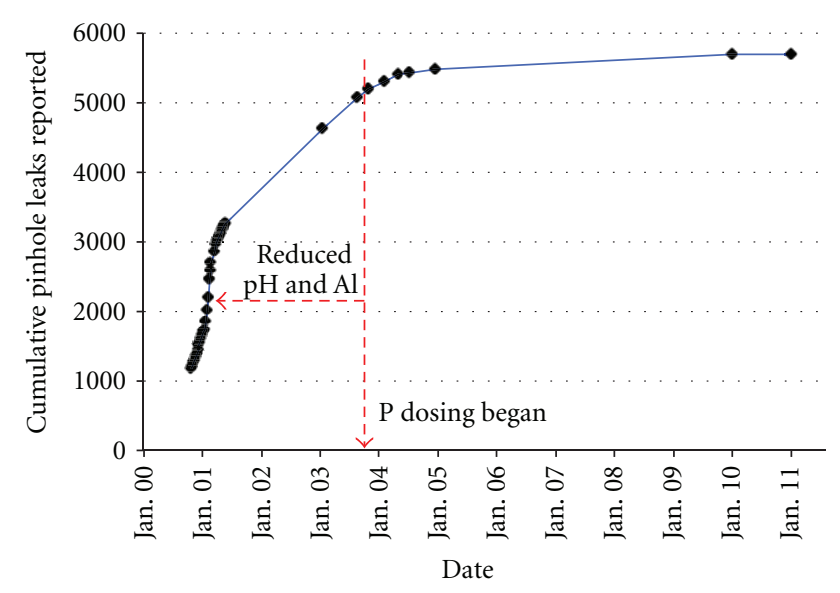

FIGURE 8: Cumulative volume of reported pinhole leaks to a utility between 2000-2011. Following introduction of phosphate at the water treatment facility, leak reports quickly declined.

reduction) also seemed to quickly reduce pitting problems [37]. Additionally, Lytle and Nadagouda reported that, in comparison to the Ohio community mentioned above that was experiencing pinhole failures and had no detectable phosphate in the water, a neighboring community with very similar water quality (i.e., $\mathrm{pH}$, chlorine, alkalinity) except for the presence of phosphate (i.e., about $0.4 \mathrm{mg} / \mathrm{L}$ as $\mathrm{P}$ from poly-phosphate dosing) did not generally have pinhole leaks [16]. Each of these cases provides practical evidence that supports an important role of phosphate as a pitting corrosion inhibitor.

On the other hand, phosphate (and likely silica) may not yield benefits in all cases, especially when pitting is caused by factors other than chlorinated, high $\mathrm{pH}$, and low alkalinity water. For example, a Florida utility attempted to mitigate a pinhole leak outbreak by dosing ortho- and then polyphosphate inhibitors, but little if any reduction in leaks was observed as a result [38]. In fact, during the year after the phosphate-dosing program was initiated, some anecdotal evidence suggests that pitting problems may have actually intensified based on significantly increased replumbing sales attributed to pinhole leaks [24]. The applied phosphate dose used was also relatively low at $0.1-0.3 \mathrm{mg} / \mathrm{L}$ as $P$. The failure of phosphate to alleviate pitting in this case may be due to the fact that a different mechanism of pitting may be occurring in this water (e.g., sulfate-reducing bacteria or SRB) [1], underdosing of the inhibitor, or other reasons not yet understood. The takeaway point is that phosphate is not a cure for all copper pitting problems.

Utilities should also remain mindful of the possibility of an "optimally adverse" dose of phosphate silica, or other additives conventionally categorized as anodic inhibitors. As illustrated by work presented here, it does appear that at very low concentrations these inhibitors may indeed accelerate the time-to-pinhole leak failure, even as they reduce the overall number of pits on a copper surface. Further research is certainly needed to determine what threshold values might be applicable in real potable water systems and at other
pHs, but it is possible that the most dangerous dosages are within the natural ranges for some constituents, particularly phosphate.

5.5. Natural Organic Matter. It has previously been suggested that recent trends in NOM removal from potable water may render some waters susceptible to copper pitting [10]. The current work does confirm that NOM may well reduce pitting, at least to some extent, in high $\mathrm{pH}$ waters with free chlorine. Results of the current work showed that even very low levels of NOM (i.e., $0.05-0.1 \mathrm{mg} / \mathrm{L}$ as TOC) could significantly delay pit growth-presumably by delaying the time-to-pit initiation and decelerating pit propagation. Ultralow levels (i.e., $0.005-0.01 \mathrm{mg} / \mathrm{L}$ ) appeared to actually make pitting worse (in terms of maximum pit propagation rate), indicating that an optimally adverse level of NOM may exist.

It appears that ozonation of NOM, as is commonly practiced in water treatment, reduces the capability of the resultant organics to delay pit initiation. And short-chained, simple organics (i.e., as represented by acetate and glucose herein) seem to be even less effective. Practically, this may explain why certain waters with relatively higher total organic carbon concentrations in the form of low molecular weight organics (i.e., and proportionally lesser humic content) might still be very susceptible to copper pitting corrosion. The variability in behavior between different types of organic carbon also highlights a long-acknowledged challenge in determining threshold levels of TOC that are needed to inhibit pitting in specific waters $[9,10]$. While the NOM used in the present work may be representative of that which occurs in some waters, further work is needed to verify that even all humic-dominated NOMs behave similarly. Moreover, a corrosion control strategy based on maintaining higher NOM concentrations in finished waters with free chlorine residual is not advisable at this point, due to increased potential for disinfection by-product (DBP) formation.

\section{Conclusions}

Pitting corrosion can lead to rapid failure of copper plumbing tubes, and one proven cause is aggressive potable water, characterized by high $\mathrm{pH}$, low alkalinity, and free chlorine residual. Potential mitigation strategies were investigated in this work, and results indicated the following.

(i) Reducing free chlorine residual reduces the rate and extent of pit initiation, but under continuous flow conditions, pits can eventually form in the presence of fairly low chlorine levels (e.g., $0.4 \mathrm{mg} / \mathrm{L}$ ). Furthermore, once pits have initiated, they may propagate at relatively similar rates over a range of chlorine levels.

(ii) Increasing alkalinity may decelerate the rate of pit propagation; however, even very high alkalinity may not completely inhibit pitting in chlorinated, high $\mathrm{pH}$ waters. 
(iii) Addition of sufficient phosphate or silica concentrations may completely inhibit pitting in aggressive waters by hindering pit initiation; at moderate concentrations, pit propagation may be slowed even if pits are initiated. But, at very low levels, these constituents can exacerbate pitting. Critical threshold levels have not been defined and probably depend upon specific system conditions (e.g., flow velocity and frequency, water quality).

(iv) Relatively low concentrations of NOM (as TOC) can significantly slow both pit initiation and pit propagation, but a threshold value to completely inhibit pitting has not been elucidated. Altered NOM and other types of organics may have varying effects on pitting.

(v) Given the experimental results and field data presented here, phosphate inhibition is a viable strategy for controlling copper pitting in chlorinated, high $\mathrm{pH}$, and low alkalinity waters.

\section{Acknowledgments}

The authors thank the Water Research Foundation (WaterRF) for funding experimental work under Project no. 4289. The views, conclusions, and/or recommendations expressed herein are those of the authors, and do not necessarily represent those of WaterRF. Special thanks are also extended to Kara Dodson and Caitlin Grotke for their assistance with experimental work and to Bob Buglass for provision of information and data regarding pinhole leak reports to the Washington Suburban Sanitary Commission (WSSC).

\section{References}

[1] P. Scardina, M. Edwards, D. Bosch, G. V. Loganathan, and S. Dwyer, Assessment of Non-Uniform Corrosion in Copper Piping, American Water Works Association Research Foundation, Denver, Colo, USA, 2008.

[2] B. Marshall, Initiation, propagation and mitigation of aluminum and chlorine induced pitting corrosion [M.S. thesis], Virginia Polytechnic Institute and State University, Virginia, Va, USA, 2004.

[3] D. A. Lytle and M. R. Schock, "Pitting corrosion of copper in waters with high $\mathrm{pH}$ and low alkalinity," Journal / American Water Works Association, vol. 100, no. 3, pp. 115-14, 2008.

[4] H. Cong, H. T. Michels, and J. R. Scully, "Passivity and pit stability behavior of copper as a function of selected water chemistry variables," Journal of the Electrochemical Society, vol. 156, no. 1, pp. C16-C27, 2009.

[5] E. Sarver, K. Dodson, P. Scardina, R. Lattyak-Slabaugh, M. Edwards, and C. Nguyen, "Incidence and costs of home plumbing corrosion," Journal of the American Water Works Association, vol. 103, no. 3, pp. 86-98, 2011.

[6] B. Marshall and M. Edwards, "Phosphate inhibition of copper pitting corrosion," in Proceedings of the 2006 AWWA Water Quality Technology Conference, Denver, Colo, USA, 2006.

[7] R. Lattyak, Non-uniform copper corrosion in potable water: theory and practice [M.S. thesis], Virginia Polytechnic Institute and State University, Virginia, Va, USA, 2007.
[8] B. Custalow, Influences of water chemistry and flow conditions on non-uniform corrosion in copper tube [M.S. thesis], Virginia Polytechnic Institute and State University, Virginia, Va, USA, 2009.

[9] H. Campbell, "A natural inhibitor of pitting corrosion of copper in tap water," Journal of Applied Chemistry, vol. 4, no. 12, pp. 633-647, 1954.

[10] M. Edwards, J. F. Ferguson, and S. H. Reiber, "Pitting corrosion of copper," Journal / American Water Works Association, vol. 86, no. 7, pp. 74-90, 1994.

[11] N. Murray-Ramos, Examining aspects of copper and brass corrosion in drinking water [M.S. thesis], Virginia Polytechnic Institute and State University, Virginia, Va, USA, 2006.

[12] M. Edwards, J. Rehring, and T. Meyer, "Inorganic anions and copper pitting," Corrosion, vol. 50, no. 5, pp. 366-372, 1994.

[13] M. Pourbaix, "Recent applications of electrode potential measurements in the thermodynamics and kinetics of corrosion of metals," Corrosion, vol. 25, no. 6, pp. 267-281, 1969.

[14] H. Cong and J. R. Scully, "Use of coupled multielectrode arrays to elucidate the $\mathrm{pH}$ dependence of copper pitting in potable water," Journal of the Electrochemical Society, vol. 157, no. 1, pp. C36-C46, 2010.

[15] M. Sosa, S. Patel, and M. Edwards, "Concentration cells and pitting corrosion of copper," Corrosion, vol. 55, no. 11, pp. 1069-1076, 1999.

[16] D. A. Lytle and M. N. Nadagouda, "A comprehensive investigation of copper pitting corrosion in a drinking water distribution system," Corrosion Science, vol. 52, no. 6, pp. 1927-1938, 2010.

[17] M. Edwards and J. F. Ferguson, "Accelerated testing of copper corrosion," Journal / American Water Works Association, vol. 85, no. 10, pp. 105-113, 1993.

[18] J. C. Rushing and M. Edwards, "Effect of aluminium solids and chlorine on cold water pitting of copper," Corrosion Science, vol. 46, no. 12, pp. 3069-3088, 2004.

[19] M. Edwards and P. Scardina, Non-Uniform Corrosion in Copper Piping-Monitoring Techniques, American Water Works Association Research Foundation, Denver, Colo, USA, 2008.

[20] Safe Drinking Water Act Amendments of 1986, Pub. L. No. 99-339, 1986.

[21] H. Cong and J. R. Scully, "Effect of chlorine concentration on natural pitting of copper as a function of water chemistry," Journal of the Electrochemical Society, vol. 157, no. 5, pp. C200C211, 2010.

[22] D. Atlas, J. Coombs, and O. T. Zajicek, "The corrosion of copper by chlorinated drinking waters," Water Research, vol. 16, no. 5, pp. 693-698, 1982.

[23] United States Geological Survey (USGS), National Water Quality Assessment Data Warehouse, http://infotrek.er.usgs .gov/apex/f?p=NAWQA:HOME:0:, 2011.

[24] Leland Plumbing, Personal Communication, Leland Plumbing, Osprey, Fla, USA, 2004.

[25] M. McGuire and R. Meadows (AWWARF), "Trihalomethanes survey-a progress report," in Proceedings of the Current Research in Drinking Water Treatment Conference, Cincinnati, Ohio, USA, 1987.

[26] U. R. Evans, "Inhibitors—safe and dangerous," Transactions of The American Electrochemical Society, vol. 69, no. 1, pp. 213$231,1936$.

[27] American Society for Testing and Materials, Manual of Industrial Corrosion Standards and Control, F. Cocks, Introduction to Corrosion, American Society for Testing and Materials, Washington, DC, USA, 1973. 
[28] HDR Engineering, Inc., Handbook of Public Water Systems, Wiley \& Sons, New York, NY, USA, 2nd edition, 2001.

[29] Maryland Department of Housing and Community Development (DHCD), "Task force study: pinhole leaks in copper plumbing," Report Submitted to State of Maryland, Maryland Department of Housing and Community Development (DHCD), Maryland, Md, USA, 2004.

[30] G. Korshin, J. Ferguson, and S. Perry, "Influence of natural organic matter on corrosion of copper in potable waters," Journal of the American Water Works Association, vol. 88, pp. 36-47, 1996.

[31] AWWA, APHA, and WEF, Standard Methods, American Public Health Association, Washington, DC, USA, 20th edition, 1998.

[32] ASTM Standard G46-94, Standard Guide for Examination and Evaluation of Pitting Corrosion, ASTM, Washington, DC, USA, 1994.

[33] E. J. Kleczyk and D. J. Bosch, "Incidence and costs of home plumbing corrosion," Journal / American Water Works Association, vol. 100, no. 12, pp. 122-133, 2008.

[34] M. Edwards, P. Scardina, and L. McNeill, Enhanced Coagulation Impacts on Water Treatment Plant Infrastructure, American Water Works Association Research Foundation, Denver, Colo, USA, 2003.

[35] E. Sarver, Y. Zhang, and M. Edwards, Copper Pitting and Brass Dezincification: Chemical and Physical Effects, Water Research Foundation, Denver, Colo, USA, 2011.

[36] Washington Suburban Sanitary Commission (Laurel, MD), Personal communications, January 2000-August 2011.

[37] P. Scardina and M. Edwards, "Preliminary investigation of copper pipe failures," Report, Jeff Gagley and Tellico Village, Tennessee, TN, USA, 2007.

[38] Sarasota County Utilities (SCU), FAQs: Pinhole Leaks in Copper Pipes, Sarasota County Utilities, Sarasota, Fla, USA, 2005. 

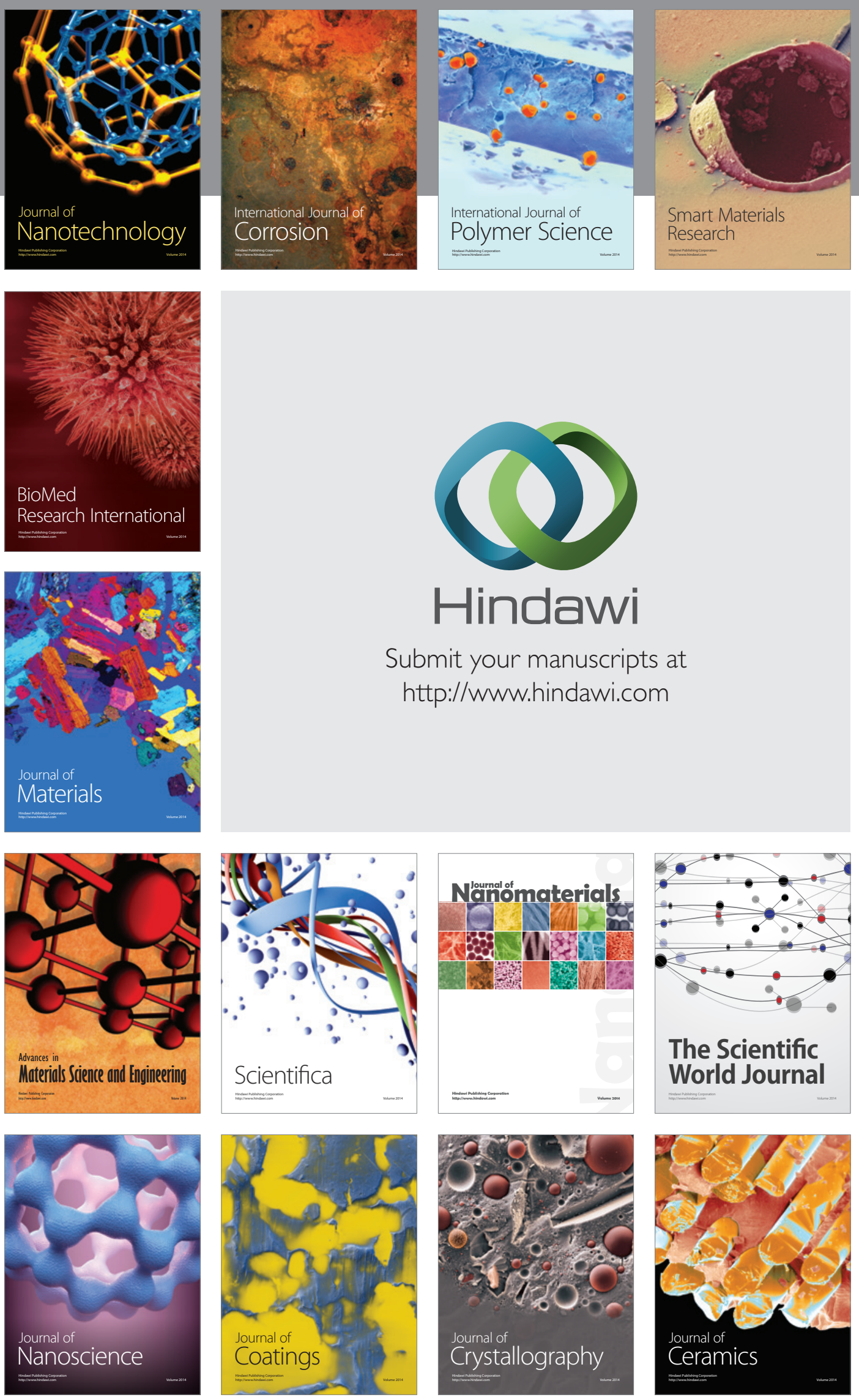

The Scientific World Journal

Submit your manuscripts at

http://www.hindawi.com

\section{World Journal}

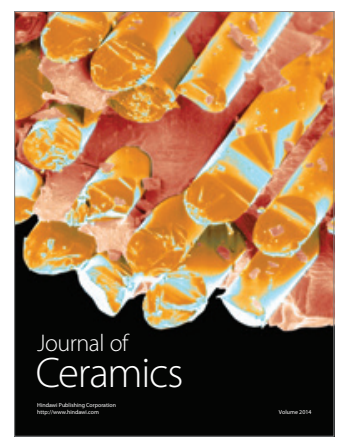

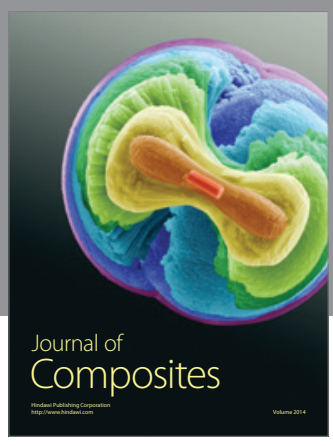
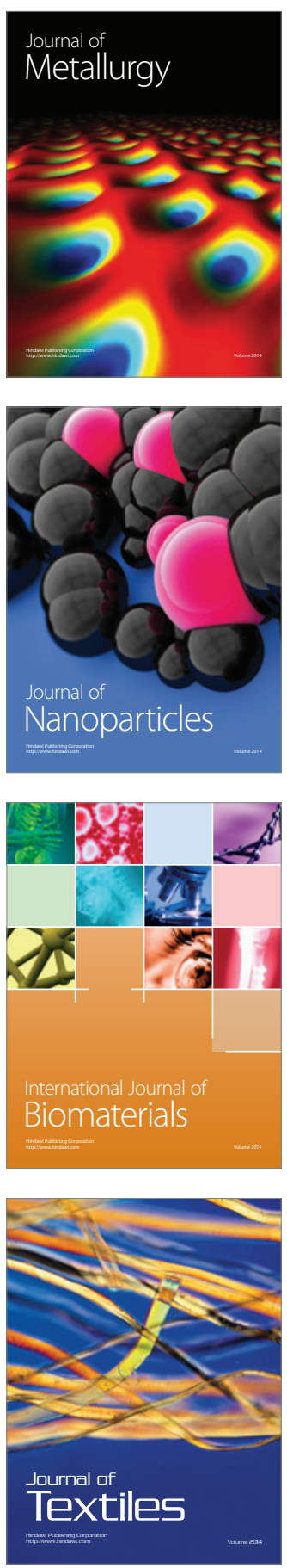